\title{
Cumhuriyet Dental Journal: A New Mission and Vision to Be a Global Journal
}

First issue of the Cumhuriyet Dental Journal (CDJ, formerly known as Journal of Cumhuriyet University Faculty of Dentistry) was published in 1998. It has been twenty years from the beginning of CDJ and the world and academia has changed during these years. We have made a very intense effort, especially in the last years, in order to follow the innovations and changes in the world and academia and to adapt them to CDJ. For this purpose, we have also made some changes in scope and vision of CDJ in the last year. CDJ currently aims to be an internationally known journal and makes every effort to achieve this aim.

As a result of our submissions, CDJ is currently indexed in internationally known SCOPUS, DOAJ and INDEX COPERNICUS and under evaluation for WEB of SCIENCE (ESCI). In 2018, the CDJ has received 172 submissions and has published 52 articles. These issues presented a wide range of high quality articles including original research articles, review and clinical case reports. CDJ has begun to publish quarterly since 2018. CDJ currently accepts articles in only English.
We hope all members of CDJ including Editors-in-Chief, Editorial Board members, authors, reviewers, and readers will help us consolidate the Cumhuriyet Dental Journal among our peers and spread it to the international community.

Editors-in-Chief, Prof. Ihsan Hubbezoglu and Assoc. Prof. Burak Buldur, would like to welcome our new prestigious Editorial Board membersProf. John Nicholson from UK, Prof. Alessandro Leite Cavalcanti from Brasil, Prof. Zafer Cehreli from Turkey and USA, and Prof. Marco Tatullo from Italy.

We would like to thank all members of CDJ and wish Happy Readings and Happy New Year in 2019.

\section{Editors-in-Chief}

Prof. Ihsan Hubbezoglu

Assoc. Prof. Burak Buldur

How to Cite: Hubbezoğlu I, Buldur B. Editorial: Cumhuriyet Dental Journal: A New Mission and Vision to Be a Global Journal. Cumhuriyet Dent J 2019:22:1:1 